\title{
PERSUASÃO VS. LÓGOS: A ATENAS DE SÓCRATES COMO CENÁRIO DE PÓS-VERDADE?
}

\section{Sergio Hugo Menna ${ }^{1}$}

\section{RESUMO}

O texto confronta o cenário epistêmico da Atenas de Sócrates com nosso contemporâneo "cenário de pós-verdade". Os conceitos chave para essa análise são os de lógos e de persuasão.

Palavras-chave: Pós-verdade. Lógos. Persuasão. Sócrates.

\begin{abstract}
This paper confronts the epistemic context of Socrates' Athens with our contemporary "post-truth world". The key concepts for this analysis are 'lógos' and 'persuasion'.
\end{abstract}

Keywords: Post-truth. Lógos. Persuasion. Sócrates.

Liberdade de palavra significa liberdade da retórica. Umberto Eco, 1995, p. 56

\section{Considerações iniciais}

O conceito de lógos é central no pensamento socrático (e platônico). Isso é evidente na famosa 'definição tripartite do conhecimento' formulada por Sócrates no Teeteto, definição que conseguiu sobreviver aos séculos e às artificiais objeções 'de tipo Gettier'.

A clássica passagem do Teeteto, 201a-c, define como 'conhecimento' a crença conectada à verdade a partir de boas razões e sólidas evidências, i.e., a crença (tida como) verdadeira por estar justificada -"ligada", "atada", “encadeada” à realidade pelo lógos (Mênon, 98a).

O caminho do lógos vai na direção do conhecimento. O lógos encadeia as crenças com as evidências que a realidade oferece.

\footnotetext{
${ }^{1}$ Doutor em Filosofia e professor do DFL/ UFS.

E-mail: sermenn@hotmail.com. ORCID: 0000-0002-7617-1450.
} 
A clássica passagem sintetiza, mas não esgota a concepção socrática de lógos e de conhecimento. Outras passagens dos Diálogos platônicos iluminam sua concepção de diferentes ângulos, seja porque a complementam, seja porque se centram no caminho oposto ao caminho do lógos: o da sofística que leva, pela via da persuasão e da mentira, à aparência, à distorção da percepção da realidade.

Nas próximas seções tentaremos esclarecer os conceitos de lógos e de persuasão na filosofia socrática, assim como suas relações. Também, tentaremos confrontar o cenário epistêmico da Atenas de Sócrates com nosso contemporâneo "cenário de pós-verdade" -em poucas palavras: com o atual conjunto de circunstâncias em que, nos processos de formação e fixação de crenças da opinião pública, as emoções e as crenças, geralmente manipuladas -persuadidas, enfeitiçadas- por algum Sistema de crença (religioso, político, econômico etc.), se impõem (epistêmica e existencialmente) aos fatos e ao lógos.

\section{Sobre o lógos (nos Diálogos platônicos)}

"Enquanto permanecem fixas como estátuas", diz Sócrates, "as crenças verdadeiras são coisas belas, mas não querem permanecer muito tempo e fogem rapidamente da alma; só têm valor quando são encadeadas com um raciocínio causal (lógos)" (Mênon, 98a; grifo meu). Por esse e outros raciocínios, como vimos, Sócrates (na voz de Platão) chega à conclusão de que o conhecimento é "crença verdadeira com um lógos" (cf., por exemplo, Teeteto, 201c). Ou, em termos mais contemporâneos, "crença verdadeira justificada".

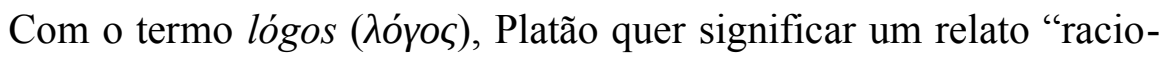
nal", "inteligível", de por que a crença é verdadeira; ou seja, ele está centrado na justificação -na razão, na explicação etc.- da afirmação que se predica conhecer. Aristóteles, na mesma linha interpretativa dele, denominou lógos $\mathrm{o}$ argumento e o discurso fundamentados.

O sufixo 'logos' está muito presente na nossa cultura. Os termos 'psicólogo', 'sociólogo', 'epistemólogo' e muitos outros finalizados em 'logo' designam os 'estudos' dos especialistas em diversas áreas do conheci- 
mento. 'Epistemólogo', por exemplo, é a pessoa especialista (lógos) na episteme, no conhecimento. Mas não caia o leitor na ilusão de pensar que a etimologia põe ordem na realidade! Pois também nos têm sido legados, entre muitos outros, os termos 'tarólogo', 'parapsicólogo' e 'astrólogo', que, como sabemos, não designam áreas de conhecimento, mas de crença e opinião, pois se referem a especialistas ...em coisas que não existem!

Os filósofos gregos -com destaque para Heráclito, Sócrates, Platão e Aristóteles-concebiam o lógos como um princípio de inteligibilidade; quem possuísse lógos -e, para eles, todos os humanos adultos compartilhamos do lógos, da mesma razão comum-, deveria ser capaz de conhecer a realidade e se orientar com prudência e benevolência pela vida.

O lógos serve para determinar o saber individual: o 'pensa por ti mesmo' socrático pressupõe o lógos. Mas também serve para determinar o saber coletivo: o diálogo humano só é possível "por intermédio" (o prefixo 'dia-' significa exatamente isso) do lógos, i.e., da palavra articulada (e livre), da conversa racional (e livre). E é nesse ponto onde se vê a forte relação que os gregos pressupunham entre o lógos e a polis, entre a razão e a coisa pública (a res publica) e a República, entre o argumento e a democracia. A arena pública, para eles, é o lugar onde o diálogo racional e livre permite encadear as crenças comuns com a realidade. Os Diálogos de Platão que registram os diálogos de Sócrates são a máxima expressão dessa cosmovisão.

Obviamente, nosso acesso à realidade poucas vezes é claro e direto. Mas a ideia detrás do conceito de lógos é que todos e qualquer um de nós poderíamos ver, compreender, entender argumentos como o seguinte:

$$
\begin{aligned}
& -\mathrm{A}>\mathrm{B} \\
& -\mathrm{B}>\mathrm{C} \\
& -\mathrm{A}>\mathrm{C}
\end{aligned}
$$

Nesse exemplo, você pode 'ver' com seu intelecto a relação entre os conceitos representados pelas letras. Também pode ver, literalmente, essa relação: faça você, leitor, a experiência de atribuir círculos de diferentes dimensões a cada letra, e sobreponha-os.

Quando compreendemos um argumento como esse, vislumbramos que os grandes gregos que definiram o conceito de lógos tinham razão. 
Como é possível que todos nós, absolutamente todos, não concordemos com essa conclusão?

\section{O lógos no Mênon}

No Mênon, Platão volta a sublinhar a distinção entre crença verdadeira e conhecimento. Essas passagens podem ser lidas como complemento e, principalmente, como ampliação de suas observações do Teeteto.

Platão começa comparando dois homens que chegam à cidade de Larisa. Um deles chegou por conhecer o caminho; o outro, por supor arbitrariamente uma direção e, simplesmente, ter tido sorte. Platão observa que os dois homens tinham uma crença: a de que Larisa se encontrava na direção à que eles se dirigiram, e que, dado que efetivamente chegaram a essa cidade, a crença de cada um deles era verdadeira. Mas, reflete ele, "mesmo que do ponto de vista da prática a crença verdadeira não seja pior guia que o conhecimento", o homem que tem conhecimento tem alguma coisa a mais do que o homem que só tem crença verdadeira (Mênon, 97b).

Quando temos conhecimento, conclui Platão, nossas crenças estão firmemente "ligadas", "atadas", "encadeadas" à realidade (98a). Essa conexão é a justificação (lógos) (98b). A justificação, o lógos socrático, faz com que, no conhecimento, a crença esteja firmemente conectada à realidade com razões e evidências, e "não fuja da alma" como as belas estátuas aladas (98a).

Para Platão, o objetivo do conhecimento é orientar nossa vida na realidade (como no caso do caminhante que vai a Larisa). Essa orientação só é possível se nossas crenças estiverem conectadas à realidade pelo lógos (cf. VILLORO 2013, p. 18-9).

\section{O lógos e sua sombra}

Embora o lógos seja comum a todos, cada um procede como se tivesse um pensamento próprio.

[...] O caminho que sobe e o caminho que desce são um único e um mesmo caminho.

Heráclito, Fr. 2 e Fr. 60 
Parece impossível que todos nós, absolutamente todos, não concordemos com um argumento evidente como o do $\mathrm{A}>\mathrm{B}>\mathrm{C}$. Porém, quando olhamos para a história ou, mais simplesmente, para nossa volta, começamos a suspeitar que talvez os filósofos gregos tenham sido demasiado otimistas, isto é, que o caminho ao conhecimento utilizando o lógos não é uma avenida ampla e bem sinalizada. Talvez todos nós concordemos em que se $\mathrm{A}>\mathrm{B}$ e $\mathrm{B}>\mathrm{C}$ então $\mathrm{A}>\mathrm{C}$, mas nestes últimos poucos anos muitos ficaram surpresos de que nem todos nós concordamos em que a Terra é redonda (hoje, $7 \%$ de nossos concidadãos acreditam piamente que é plana!), ou em que existe um vírus de nome técnico 'SARS-CoV-2' (até onde sei não existem dados estatísticos sobre as porcentagem dos que não acreditam na existência do vírus, mas todos nós vimos vídeos de pessoas que fazem carreatas em frente aos hospitais levados pela cega convicção de que o vírus -que mostra seu poder de devastação em todos os países e até nas cidades em que são realizadas as carreatas- não existe, porque é chinês, porque é comunista ou por outros motivos que só fazem sentido na escuridão de suas cabeças, mas não na clara e distinta realidade). Será que nem todos os humanos adultos compartilham do lógos? Será, como disse Kant no O que é Iluminismo?, que a maioridade (intelectual) não é uma questão de idade mas de responsabilidade (e liberdade)? Será, como disse Dodds, que a liberdade intelectual implica "uma aterrorizante carga de responsabilidade diária" da qual muitos preferem fugir? (cf. 1997, p. 230). Talvez não por acaso Heráclito -que defendia que o lógos era comum a todos os homens- era chamado de 'obscuro’ por seus contemporâneos...

Acaso não é verdade que "cada [homem] procede como se tivesse um pensamento próprio", como disse Heráclito? Pelo menos nos últimos anos, pareceria que não é o lógos comum o que fundamenta as decisões individuais e coletivas. Nos bastidores das escolhas humanas, inclusive das mais transcendentes, todos nós podemos reconhecer arbitrariedades, paixões, crenças nas crenças, delírios, alienação. E também podemos reconhecer que tais paixões e crenças são manipuladas e controladas por Sistemas de poder; religiões organizadas, partidos políticos que já não jogam o jogo da política, o mercado. Por isso, 'o fenômeno pós-verdade' que aparentemente caracteriza nossa época bem poderia ser reformulado como o fenôme- 
no "de perda, ou de diminuição, ou de ocultamento do lógos". Um abatido Umberto Eco, menos diplomático, falou de "uma invasão de imbecis" (cf. 2015). Frase eticamente incorreta para quem afirmou que "a dimensão ética começa quando o outro entra em cena" (1997, p. 208), mas que neste contexto de distorção extrema podemos compartilhar e desculpar.

\title{
Sobre a persuasão (nos Diálogos platônicos)
}

\begin{abstract}
-Sócrates: Imaginemos que um mestre da retórica, que não sabe o que é o bem nem o que é o mal, vai a uma cidade que tampouco sabe nada disso. E imaginemos que esse mestre, tendo estudado as opiniões das pessoas, as persuadisse sobre o mal como se fosse o bem, e assim, as levasse a fazer o mal no lugar do bem (o que é a mesma coisa que se as tivesse persuadido de que a "sombra de um asno" (Aristófanes, Vispas, 191) é na realidade um cavalo). Que tipo de frutos você acha que a retórica colheria do que semeou?

-Fedro: Com certeza, não seriam muito bons...

Platão, Fedro, 260d
\end{abstract}

Para compreender a importância que Sócrates concede ao conceito de lógos, podemos indagar suas críticas às técnicas de persuasão dos sofistas de sua época.

Sócrates entende que a finalidade da sofística é a persuasão (peithó) e a mentira (ápaté) (Sofista, 234b-c). "Persuadir", define Sócrates no Teeteto, "é levar uma pessoa a adotar uma crença" -uma crença que não é conhecimento (201c). A persuasão "é como um feitiço", pois faz com que uma pessoa mude de crença sem se dar conta disso (República, 413b).

No pensamento mítico, Peithó, a Persuasão, é uma divindade que tem o poder de encantar, de convencer as pessoas, de "enfeitiçar com palavras de mel” (ESQUILO, fr. 297). Mas, em definitiva, tais palavras "de mel" são, como disse Hesíodo, “palavras de engano" (Trab., 77-78), não de verdade e liberdade (cf. DETIENNE 1981, p. 69-70).

Os "mestres da persuasão", segundo Sócrates, não se interessam pela verdade das ideias que propõem e relativizam a realidade; eles só se esforçam em convencer, sem se preocupar com a natureza dos meios utilizados e sem se importar com a concordância do discurso com a realidade. Sócrates denominava 'sofistas' os oradores, políticos, advogados e todo aquele que conhece as técnicas retóricas da persuasão e que não se sente comprometido com o dever da verdade. Poderíamos atualizar a lista socrática acrescentan- 
do como "mestres da persuasão" os youtubers, gurus, coachs e influenciadores contemporâneos.

Para Sócrates, os sofistas são homens da doxa: da crença, da opinião, da ilusão, da aparência e até da mentira. Não há, no discurso deles, lugar para a verdade (aletheia) e o real conhecimento (episteme). O sofista "só possui um conhecimento aparente sobre todas as coisas; não possui a verdade" (Sofista, 233c; grifo meu), afirma Sócrates. E complementa em outra passagem: "Pois a persuasão vem das aparências, não da verdade" (Fedro, 260a).

Para Sócrates, pelo fato de "ignorar a verdade" (Fedro, 260a), o sofista não ensina, i.e., não transmite conhecimento, pois o conhecimento somente se transmite (e se adquire) por intermédio do ensino que vai acompanhado do lógos. O sofista só transmite crenças, crenças que são fixadas nos ouvintes pela persuasão. E essas crenças "são carentes de lógos" (Timeo, 5le). O sofista unicamente persuade. Mas dessa persuasão só "nasce a crença sem o saber" (Górgias, 454e). (Essa crença, é bom destacar, tanto pode ser verdadeira quanto falsa, pois está desligada de qualquer justificação que a aproxime do conhecimento). O sofista só está a favor das crenças - de crenças que, por não estar conectadas com a realidade mediante o lógos comum a todos os homens, não são conhecimento (cf. Teeteto, 201b-c e Górgias, 454e-455a).

Sócrates, evidentemente, não gostava das técnicas de persuasão dos sofistas (curiosamente, era amigo de vários sofistas; ironicamente, muitos o acusavam de ser sofista). Por isso em seus diálogos encontramos inúmeras referências negativas: o sofista só oferece uma "vã aparência de sabedoria" (Sofista, 231c), é "um contrabandista das mercadorias das quais a alma se nutre" (Protágoras, 313c), é um "sabichão", um "buscador de contradições" (Lisis, 216a) que "está sempre à caça de opiniões" (Fedro, 262c). Por isso, "por ignorar a verdade, a arte das palavras que oferece [o sofista...] é algo ridículo e grosseiro" (Fedro, 262c).

O orador "não necessita conhecer os temas sobre os quais ele fala, só dominar as técnicas de persuasão" (Górgias, 459c). "O orador tem a capacidade de "persuadir multidões" (Górgias, 457b). Ele tem como objetivo "a persuasão de membros de um júri, de uma assembleia ou de qualquer outro 
tipo de pessoas reunidas" (Eutidemo, 290a). São os oradores, observa Sócrates, que aconselham nas assembleias quando há que se escolher generais para uma batalha, e não, como seria razoável esperar, os especialistas em guerra; "e ainda pior: os oradores têm a capacidade de persuadir um doente com maior facilidade do que o próprio médico" (Górgias, 455e-456c). Mas, como o sofista não tem conhecimento dos assuntos sobre os quais fala, seus procedimentos de persuasão somente "o fazem parecer saber mais do que realmente sabe", e somente "aos olhos dos seus ignorantes ouvintes" (Górgias, 459d; grifo meu). Ou seja, Sócrates parece acreditar que as técnicas sofistas só conseguem convencer os ignorantes, os quais não têm conhecimento sobre determinados assuntos -inclusive menciona que seus principais ouvintes são os jovens inexperientes (Teeteto, 234d). O feitiço das palavras dos sofistas não tem efeito nos especialistas, naqueles que conhecem as causas das coisas que conhecem, i.e., naqueles que compreendem o lógos.

Destaco que nas passagens anteriores, quando caracterizei os sofistas, utilizei sempre expressões como 'para Sócrates' ou 'segundo Sócrates'. Fiz isso, basicamente, porque estou interessado na contraposição entre persuasão e lógos desenvolvida por Sócrates. Mas, pelo menos no que respeita à displicência com relação à importância da verdade, Górgias, o principal representante da sofística, não esconde que a verdade não está no centro de seus interesses. Em seu Elogio de Helena, por exemplo, ele faz os seguintes comentários: "um discurso escrito com arte [retórica], mesmo que não diga a verdade, consegue persuadir uma grande multidão" (§13; grifo meu); “[os sofistas] fazem aparecer coisas incriveis e invisíveis aos olhos da opinião, destruindo uma crença e fazendo surgir outra crença em seu lugar” ( $\$ 13$; grifo meu); e, finalmente, "a persuasão, aproximando-se pelo discurso, [...] enfeitiça completamente a alma" (§13-14).

É importante destacar que Sócrates parece abrigar certa esperança no aprendizado do exercício do lógos -o equivalente antigo a ter confiança na importância do ensino de raciocínio crítico. Ele acredita que o jovem, tendo um contato "diáfano" com a realidade -i.e., um contato límpido, não mediado pelas distorções da persuasão-, poderá ganhar experiência e, quando adulto, poderá mudar suas falsas crenças fixadas pelos sofistas: "Será neces- 
sário, Teeteto, que os [jovens] ouvintes, uma vez que um tempo tenha passado e tenham atingido uma certa idade, ao encarar as coisas mais de perto, e vendo-se forçados pela experiência a estabelecer um contato diáfano com a realidade, mudem as opiniões recebidas" (Teeteto, 234d; grifo meu).

Uma observação só em carácter informativo: na filosofia posterior, a persuasão do orador e a convicção que emana do lógos foram vistas como extremos de um continuum mais do que como caminhos opostos. Depois de tudo, como afirmou Aristóteles, a persuasão "é uma espécie de demonstração, pois certamente ficamos completamente persuadidos quando consideramos que algo nos foi demonstrado". Ou seja, tanto o orador quanto a inferência lógica podem persuadir -o que equivale a afirmar que o problema não se encontra na convicção da crença, mas na qualidade da fonte de persuasão utilizada para fixar tal crença.

Em resumo e finalizando: Sócrates, mestre da verdade, punha a chave da pedra filosofal no conhecimento; os sofistas, mestres da persuasão e da mentira, no poder $^{2}$. Essas duas vias filosóficas continuam em toda a história da filosofia, com os racionalistas, empiristas, iluministas etc. do lado socrático, e com os relativistas, perspectivistas e pós-modernos do lado sofista.

\section{Um cenário de pós-verdade?}

Houve uma outra vez na história, [na Grécia do século III a.C.], um povo civilizado que caminhou para o mesmo salto -caminhou para ele e enfim se recusou a dá-lo. [...].

Quem se recusou a saltar foi o 'cavalo' ou o 'cavaleiro'? Eis ai a questão crucial. Pessoalmente acredito que foi o 'cavalo -em outras palavras, os elementos irracionais da natureza humana que governam, sem que o saibamos, muito de nosso comportamento e muito daquilo que acreditamos pensar. E se estou certo quanto a isto, não consigo ver muita base para esperança.

E.R. Dodds, 1997, p. 238

\footnotetext{
${ }^{2}$ Podemos considerar Platão um mestre da verdade? Sim o jovem Platão, que acompanhou (física e mentalmente) Sócrates na Apologia e nos primeiros textos socráticos. Dificilmente o velho Platão, o desiludido Platão da República, criador da cruel e elitista "nobre mentira" do 'mito dos metais' (cf. 414b). Alguns objetarão que foi Sócrates e não Platão que defendeu tal "mentira imprescindível", mas não parece possível que o Sócrates que aceitou serenamente a cicuta para ser consistente com seus princípios tenha se desviado tanto do farol da verdade que dava sentido à sua vida. Argumentamos que só o fato de colocar na voz de Sócrates tal "falsidade imprescindível" aproxima ainda mais Platão dos mestres da mentira do que gostaríamos de reconhecer.
} 
O conceito de pós-verdade é novo, mas muito conhecido. Pretende retratar o seguinte cenário epistêmico: temos pós-verdade nas circunstâncias históricas em que as emoções, os desejos e nossas redes de crenças têm mais influência na formação de crenças (individuais e coletivas) do que os fatos objetivos -o antigo farol que orientava em direção à verdade. Tal confluência de circunstâncias se dá, segundo seus defensores, neste estranho e mal início do século XXI que todos nós (mal) compartilhamos.

Sócrates, como vimos, confronta o lógos com a persuasão. Aqui, o lógos equivale a qualquer processo de justificação que consiga 'encadear' as crenças com a realidade, condição que permite afirmar que podemos considerar (mas sem garantias) essas crenças como verdadeiras. Já a persuasão é criticada por Sócrates como um processo epistemicamente inválido, realizado mediante técnicas retóricas que conseguem "enfeitiçar" os ouvintes, fazendo com que acreditem em falsidades e aparências. Encontravam-se Sócrates e seus concidadãos em um cenário de pós-verdade análogo ao cenário em que supostamente estamos agora?

Talvez não. É certo que temos, nesse velho cenário helenístico, um confronto entre os mesmos componentes epistêmicos: os fatos objetivos, encadeados ao conhecimento pelo antigo e luminoso lógos, e as emoções, os desejos e as crenças influenciadas pelas técnicas de persuasão manipuladas pelos obscuros interesseiros de sempre.

Os mesmos elementos estão presentes nos dois cenários; porém, com pesos diferentes. O prefixo 'pós', no termo 'pós-verdade', pretende enfatizar que no atual cenário de pós-verdade o clássico mecanismo fatos objetivos + lógos é ofuscado pelas técnicas de persuasão hoje turbinadas pela tecnologia informática. Em outras palavras, que no cenário atual a persuasão consegue se impor ao lógos porque as técnicas de controle são muito mais sofisticadas, porque o domínio da psicologia de persuasão de crenças por parte dos manipuladores é superior e, principalmente, porque o desinteresse geral daqueles que serão prejudicados caso se instale alguma variante de fascismo beira o cinismo niilista. Em síntese: que no cenário atual a correlação de forças não é simétrica como foi no cenário socrático.

Argumentei que apesar dos mesmos elementos estarem presentes nos cenários socrático e contemporâneo, seus pesos são diferentes. Esse ar- 
gumento pode ser complementado apontando em direção ao otimismo de Sócrates, otimismo moderado, mas sistemático.

Sócrates reconhece que a situação epistêmica de sua época é complexa. Ele chega até a mencionar que o sofista pode fazer parecer com que "a sombra de um jumento seja em realidade um cavalo" (Fedro, 260d). Ou seja, reconhece que o sofista tem a capacidade de distorcer deliberadamente a percepção da realidade de seus ouvintes. Mas, apesar disso, na maioria das passagens mantém um concentrado otimismo, no meu entender, baseado em sua crença ingênua de que na realidade o lógos, assim como acontece com os bons só na ficção, poderá mostrar seu valor, e finalmente se imporá. Para ele, como vimos, a experiência e os fatos são antídotos contra a mentira e a impostura. Por isso, acredita que o feitiço das palavras dos sofistas não tem efeito naqueles que têm conhecimento e por isso são livres. E tem a esperança de que os jovens inexperientes, principais vítimas da persuasão sofista, quando adultos, e com o devido contato com a realidade, estarão em condições de mudar suas falsas crenças.

\section{Considerações finais}

Pelo que sabemos da vida de Sócrates, o seu otimismo epistêmico teve um final abrupto. Tendo conseguido sobreviver à cruenta peste do ano 430 a.C., não conseguiu sobreviver às manipulações retóricas de seus inimigos, que escreveram seu destino de cicuta e morte. Pelo que sabemos da decadência da Atenas outrora de ouro, o lógos mal conseguiu manter seu esplendor até a morte de Aristóteles. Depois, em poucas décadas, no cenário que hoje poderíamos qualificar de pós-verdade, crenças pseudocientíficas como a astrologia "caíram sobre a mente helenística como uma nova doença cai sobre os habitantes de uma ilha remota" (MURRAY, 1955, p. 239). Mas o irracionalismo também se apoderou da alma helenística, que "por um ou mais séculos tinha ficado face a face com sua própria liberdade intelectual": “agora virava as costas e fugia dessa horrenda perspectiva -melhor o rígido determinismo do Destino astrológico do que a aterrorizante carga de responsabilidade diária" (DODDS, 1997, p. 230). Depois de tudo, Aristóteles tinha 
alertado em sua Metafísica que só se pode manter uma vida baseada na razão por períodos muito curtos $\left(1072^{\mathrm{b}}\right)$.

\section{Referências}

CORNFORD, F.M. (2007) La teoría platónica del conocimiento. Barcelona: Paidós.

ECO, U. (1995) El fascismo eterno, in ECO, U. (1997) Cinco escritos Morales. S.P.: Titivillus.

ECO, U. (1997) Cuando entra en escena el otro, in ECO, U. (1997) Cinco escritos Morales. S.P.: Titivillus.

ECO, U. (2015) Conferência de entrega do doutorado honoris causa. Universidade de Turim (10/06/2015).

GÓRGIAS (2009) Elogio de Helena, Anágnosis. Belo Horizonte: UFMG, $<$ http://anagnosisufmg.blogspot.com/2009/10/elogio-de-helenagorgias.html>.

DETIENNE, M. (1981) Los maestros de verdad en la Grecia arcaica. Madrid: Taurus.

DODDS, E.R. (1997) Los griegos y lo irracional. Madrid: Alianza.

GUTHRIE, W.K. (1992) Historia de la filosofía griega, V. Madrid: Gredos.

MURRAY, G. (1955) Five Stages of Greek Religion. NY: Dover.

PLATÓN (1997-9) Diálogos: Obras completas, VII. Madrid: Gredos.

VILLORO, L. (2013) Presentación, in VILLORO, L. (ed.) El conocimiento. Madrid: Trotta, 11-4. 